\title{
Sobre semântica: perspectivas e interfaces
}

On semantics: approaches and interfaces

Doutora em Linguística pela Pontifícia Universidade quisadora Sênior na Medo Sul (PUCRS). PesAmherst. Professora Titular do Programa de PósGraduação em Letras, Escola de Humanidades, PUCRS, Porto Alegre, RS, Brasil. Did htt:///orcid.org/0000-0001-9645-136 E-mail:atibanos@pucrs.br

Doutora em Letras (PUCRS/CNPq) e pós-doutora pelo Programa de Pós-Graduação em Inglês University International College, RAEM, Macau, (i) http://orcid.org/0000-0001-5642-8848 E-mail: mdsmonawar@must.edu.mo

Mestra em Letras pelo Programa de Pós-Graduação em Letras da Universidade Federal de Pelotas (Uística ProgramaAES). Doutoranda em LinEscola, de Humanidades, PUCRS (CNPq). Porto Alegre, RS, Brasil. (1) http:///orcid org/0000-0002-0731-1800 E-mail: vergilia_sls@yahoo.com.br

Recebido em: 14/6/2019 Aprovado em: 20/6/2019

Endereço para correspondência: Programa de Pós-Graduação em Letr Ev. Ipirngumanidades - PuCRS

A0619-900, Porto Alere RS, Bras
Ana Maria Tramunt lbaños ${ }^{1}$ Monica Monawar ${ }^{2}$ Vergília Spiering Damé ${ }^{3}$

1,3Pontificia Universidade Católica do Rio Grande do Sul, Escola de Humanidades, Porto Alegre, RS, Brasil. ${ }^{2}$ Universidade de Ciência e Tecnologia de Macau, University International College, Macau, China.

"To make biological survival possible, Mind at Large has to be funnelled through the reducing valve of the brain and nervous system. What comes out at the other end is a measly trickle of the kind of consciousness which will help us to stay alive on the surface of this particular planet. To formulate and express the contents of this reduced awareness, man has invented and endlessly elaborated those symbol-systems and implicit philosophies which we call languages. Every individual is at once the beneficiary and the victim of the linguistic tradition into which he or she has been born - the beneficiary inasmuch as language gives access to he accumulated records of other people's experience, the victim in so far as it confirms him in the belief that reduced awareness is the only awareness and as it be-devils his sense of reality, so that he is all too apt to take his concepts for data, his words for actual things."

(Aldous Huxley, The Doors of Perception \& Heaven and Hell)

nvestigações em linguagem podem ser vistas, em última instância, como investigações sobre a humanidade; a constante busca pelo entendimento de nós mesmos, de nossas mentes/cérebros e de nossas identidades, das nossas relações com mundos, das realidades, do tempo e dos outros e dos nossos múltiplos contextos. É esse entendimento que encapsula nossas precisões e nossas vaguezas, nossas comparações, nossos contrapontos e nossas escalas. A busca sobre o que é o significado ou o sentido, como o elaboramos e como processamos, como é codificado verbal, funcional e/ou socialmente compreende o fio condutor que une a trama de trabalhos presentes neste volume.

Trata-se de um volume sobre semântica, que reconhecemos como um subteoria linguística que, grosso modo, é reconhecida como a área do significado. Subteoria da linguística, porque assumimos que a linguística representa um 
conjunto variado de teorias não homogêneas. Tais teorias e linhas de investigação não coincidem quanto à forma como o seu objeto é constituído e nem quanto ao modo de abordá-lo, mas nem por isso deixam de pertencer ao conjunto que identifica uma ciência linguística.

O debate acerca do que estaria ou não no escopo dos estudos em semântica de línguas naturais não é recente e está em constante movimento. Essa construção dá-se de diversas formas e perspectivas que, por vezes, competem e, por outras, se complementam. Seja o viés formal, cognitivo, social ou outro, os estudos em semântica seguem problematizando e desvendando novos modos de descrever, analisar e discutir o significado e o sentido na e pela "língua(gem)".

Esta edição evidencia a trama multifacetada dos estudos atuais em semântica em português, seja em interfaces com outras áreas de pesquisa como a Lógica, a Comunicação e a aquisição da linguagem, seja em articulações com estudos em outras subdisciplinas da Linguística, como a sintaxe e a pragmática, por exemplo. Ainda, encontram-se aqui trabalhos que revisitam e revigoram debates estabelecidos acerca de fenômenos semânticos como, por exemplo, expressões graduadoras, papeis temáticos e funções enunciativas. O funcionamento da língua está aqui descrito e argumentado com base em diferentes vertentes, em um arranjo que vai desde aquelas que se aproximam da lógica e da filosofia analítica até as dialéticas e situadas sócio, histórico, político e culturalmente. Busca-se, em comum, através do pensamento científico sobre linguagem e língua, ampliar e até mesmo, por vezes, refazer caminhos explanatórios sedimentados pela gramática tradicional em abordagens que, muitas vezes, limitam em vez de delimitar os processos através dos quais elaboramos e produzimos significado e/ou sentido nas línguas naturais.

Desta forma, neste volume, estão reunidos trabalhos que discutem fenômenos semânticos em termos de constituição, construção, codificação de significado ou sentido e as suas aplicações e desdobramentos para os estudos em semântica, mas também em articulação com sintaxe, léxico, aquisição da linguagem, análise do discurso e outras conexões e interfaces em potencial.

De forma alguma seria possível chegar aqui à exaustão das descrições, análises e discussões em semântica. De maneiras cada vez mais compreensivas e ao mesmo tempo detalhadas, os estudos em linguagem beneficiam-se de articulações ontológica e metodologicamente complexas com outras áreas de estudo dentro e fora da Linguística, promovendo interfaces, como algumas que vemos aqui instanciadas.

$\mathrm{O}$ artigo que abre esse número, dedicado à semântica, é de autoria de Rove Chishman, pesquisadora convidada a colaborar com essa edição devido ao trabalho desenvolvido acerca da temática. O texto apresentado por ela, "A visão enciclopédica de frames semânticos", traz uma reflexão sobre a interface da semântica de frames com a lexicografia, podendo ser dividido em duas partes: uma teórica e outra aplicada. No primeiro momento, a autora situa o leitor acerca 
da relevância da linguística cognitiva. Em seguida, são apresentados dois estudos de caso que atestam a importância do frame semântico, em especial, para a lexicografia eletrônica, revelando que a semântica cognitiva, de um modo geral, tem muito a ofertar para estudos lexicográficos.

Adriana Tavares Maurício Lessa, em artigo intitulado “A Hipótese da Primazia do Aspecto e Telicidade: um estudo de caso duplo", aborda os limites entre a sintaxe e a semântica formal no que se refere ao aspecto. Para tanto, observa a emergência verbal a fim de verificar: (i) a pertinência da hipótese de primazia do aspecto, que indica que a marcação do tempo/aspecto é de responsabilidade unicamente do aspecto lexical do verbos e (ii) a associação entre aspecto lexical e gramatical, indiciando que a aquisição do aspecto está pautada na relação entre a telicidade e a perfectividade. A fim de discutir as hipóteses traçadas, são analisados dados de produção verbal da aquisição inicial (1 ano e 6 meses a 2 anos e 2 meses), que abrangem a língua portuguesa e inglesa.

O tratamento da vagueza na linguística é discutido por Nanashara Behle que, para isso, alia pressupostos dessa área com aqueles estabelecidos pela lógica. Em seu artigo "Paradoxo de Sorites: uma reflexão semântica sobre a vagueza", ela discorre sobre como predicados de vagueza são recorrentes na nossa comunicação cotidiana, avaliando os encadeamentos soríticos que os regem. Desse modo, a fim de ilustrar a vagueza presente em nossa linguagem, a autora faz uso do Paradoxo de Sorites, buscando demonstrar a eficácia da aliança entre as duas áreas de conhecimento - lógica e linguística - privilegiadas em seu texto.

Yuri Penz, no artigo "Hologramas semânticos: uma proposta metateórica para a avaliação do significado complexo na linguagem natural”, também privilegia a relação entre a lógica e a linguística, demonstrando como a semântica formal possibilita observar a relação causal por meio da modalidade. Explicita, para tanto, a importância de considerar a sintaxe conjuntamente com a pragmática, para que a união entre regras formais e contexto proporcione uma adequada interpretação semântica.

O trabalho seguinte, de autoria de Luisandro Mendes de Souza, "Locuções graduadoras coloquiais", demonstra o papel intensificador assumido pelas locuções graduadoras iniciados por "para/pra” (pra caramba) e "a” (à beça). A partir de critério semântico exposto por Guimarães (2007), o autor aponta que essas expressões podem ser interpretadas semanticamente da mesma forma que "muito", enquanto indicador de grau. Além disso, o pesquisador coloca em discussão a ideia de que o grau está relacionado semanticamente apenas com adjetivos e advérbios, indiciando que pode modificar também predicados de outras classes sintáticas.

A relação entre a sintaxe e a semântica, também está presente no artigo de Rerisson Cavalcante, Débora Trindade Gomes e Cristina Figueiredo intitulado "Sobre o papel temático da preposição 'com'". No texto, os autores têm por hipótese 
que a preposição "com", independentemente do contexto em que está inserida, deve ser caracterizada pelo traço de "participante do evento", apresentando sempre a mesma contribuição semântica aos seus complementos. Em defesa de sua hipótese demonstram como tratar o papel da preposição "com" na forma de implicaturas canceláveis, sendo excluída a possibilidade de polissemia por meio de informações contextuais.

O artigo "A prospecção de $\mathrm{O}$ aparelho formal da enunciação" apresentado por Fábio Aresi aborda o texto "O aparelho formal da enunciação" de Benveniste (1970), estabelecendo os ganhos obtidos por tal publicação, na qual as definições acerca da enunciação são feitas de maneira mais direta, e os pontos prospectivos oriundos de tal obra. Para tanto, o autor revisita o texto com um olhar crítico, destacando quatro pontos, que deixam possibilidade para novas abordagens no viés enunciativo. São esses pontos: o aspecto da realização vocal da língua, o aspecto da semantização da língua, o aspecto redimensionado do quadro de realização da língua, e o último parágrafo do texto, que trata de possibilidades de estudo no campo enunciativo.

Luciani Dalmaschio e Vic Stussi de Mello Martins discorrem acerca da produtividade do objeto verbal no artigo seguinte, intitulado "O Lugar de Objeto e a Materialização Linguística dos Sentidos em Fuga". Como o título aponta, o principal objetivo é observar como o lugar sintático de objeto revela-se um caminho de fuga de sentidos, aos moldes propostos por Orlandi (2012), no qual as quebras de referenciais já estabelecidos são esperadas para dar lugar a novas possibilidades de significados. Para isso, é realizada uma análise sintático-semântica de textos coletados em diferentes mídias, evidenciando sentidos de fuga manifestados por meio da polissemia, do silêncio e, por fim, a principal contribuição do artigo, aqueles decorrentes de fuga no lugar de objeto verbal.

O artigo que finaliza esta edição, "A identidade das formas linguísticas sob o ponto de vista das operações predicativas e enunciativas", trata da variação radical de formas linguísticas com base na Teoria das Operações Predicativas e Enunciativas (TOPE). Os autores, Albano Dalla Pria, Marcos Luiz Cumpri e Taisir Mahmudo Karim, discutem acerca dos valores do substantivo "cachorro" e dos artigos "o" e "um" a partir de simulações enunciativas em que demonstram a dinamicidade presente na linguagem.

Expostos os trabalhos que compõem esta edição fica novamente evidente o amplo escopo que a semântica representa e como é capaz de proporcionar interlocução com distintas áreas. Esperamos que as contribuições aqui apresentadas se transformem em discussões cada vez mais frutíferas e que sentidos e significados sigam sendo problematizados e desvendados.

Boa leitura! 